\title{
A formação de professores de ciências a partir de uma perspectiva de Educação em Direitos Humanos: uma pesquisa-ação
}

\author{
The training of science teachers within a perspective of \\ Education in Human Rights: an action research project
}

\author{
Roberto Dalmo Varallo Lima de Oliveira ${ }^{1}$ \\ http://orcid.org/0000-0002-8348-966X \\ Gloria Regina Pessôa Campello Queiroz ${ }^{2}$
}

\begin{abstract}
Resumo: O presente artigo defende que a elaboração de uma disciplina, estruturada a partir de uma perspectiva de Educação em Direitos Humanos (EDH) e presente na formação inicial de professores de Ciências, poderia favorecer a reflexão dos licenciandos sobre seu papel como Agentes Socioculturais e Políticos. Este trabalho é caracterizado como pesquisa-ação e possuiu como objetivo prático a elaboração de uma disciplina que possibilitasse, durante a formação inicial do professor de Ciências, uma abordagem baseada na perspectiva de EDH. O projeto foi implementado em uma Universidade Pública da região Norte do país e possibilitou, durante as reflexões sobre a formação dos professores, identificar aspectos que favoreceram e dificultaram tal processo. Destaca-se que a ação formativa foi entremeada por valores provenientes das diversas relações sociais e gerou posturas como: silenciamentos, resistências, transformações e princípios de coformação, e existência de fragmentação na formação dos valores sociais dos participantes.
\end{abstract}

Palavras-chave: Pesquisa-ação. Ensino de ciências. Educação em direitos humanos. Formação de professores.

\begin{abstract}
In this article, we defend the elaboration of a discipline, structuring it from a perspective of Education in Human Rights and present it to initial training of Science teachers, to help the reflection of the graduates about their role as Sociocultural and Political Agents. This work is characterized as Action Research and its practical goal is the elaboration of a discipline that allows, during the initial training of Science teachers, an approach based in the perspective of Education in Human Rights. We highlight that the training process was interspersed with values derived from the different social relationships and created positions such as: silencing, resistance, transformations and principles of co-formation. Also the existence of a fragmentation in the formation of the social values of the participants, so that different themes generated different reflections and attitudes during the training (called the kaleidoscopic dimension).
\end{abstract}

Keywords: Action-research. Science teaching. Education in human rights. Training of science teacher.

\footnotetext{
${ }^{1}$ Universidade Federal de Uberlândia (UFU), Campus Pontal, Ituiutaba, MG, Brasil. E-mail: < robertodalmo@ ufu.br>.

${ }^{2}$ Universidade do Estado do Rio de Janeiro (UERJ), Rio de Janeiro, RJ, Brasil.
} 


\section{Introdução}

O presente artigo relata uma pesquisa-ação desenvolvida no âmbito da formação de professores de Ciências da Natureza na qual foi implementada uma disciplina sobre Educação em Direitos Humanos. Ministrada no primeiro período de 2015, tal disciplina já possuiu ênfase em aspectos das Diretrizes Curriculares Nacionais para a formação inicial em nível superior (cursos de licenciatura, cursos de formação pedagógica para graduados e cursos de segunda licenciatura) e para a formação continuada de professores, de 1 de julho de 2015. Entre tais aspectos destaca-se o artigo $5^{\circ}$, parágrafo V, pelo valor dado “[...] à consolidação da educação inclusiva através do respeito às diferenças, reconhecendo e valorizando a diversidade étnicoracial, de gênero, sexual, religiosa, de faixa geracional, entre outras” (BRASIL, 2015, p. 6).

A proposta pode ser entendida a partir dos objetivos: (i) prático - elaborar uma disciplina que possibilitasse a formação inicial do professor de Ciências, a partir da Perspectiva de Educação em Direitos Humanos - produção da ementa e de um conjunto de oficinas pedagógicas; e, (ii) de conhecimento - Analisar a implementação da disciplina a partir da gravação das aulas e de entrevistas com estudantes-colaboradores no intuito de compreender o processo de formação inicial de professores de Ciências nessa perspectiva.

Essa pesquisa-ação foi elaborada em nível de Doutorado por Oliveira (2017) e teve como base a hipótese de que uma disciplina estruturada a partir de uma perspectiva de Educação em Direitos Humanos, estando presente na formação inicial de professores de Ciências, favorece a reflexão dos licenciandos sobre seu papel como agentes socioculturais e políticos.

Dessa forma, nosso artigo será composto pelas seguintes seções: referenciais teóricos, na qual serão delineados aspectos do modelo Agente Sociocultural e Político (ASCP) desenvolvido no âmbito da pesquisa em Educação por Candau et al. (2013) e pensado para o contexto específico da Educação em Ciências por Oliveira e Queiroz (2016a); a pesquisa-ação e seus pressupostos teóricos, na qual defenderemos os motivos pelos quais nosso trabalho pode ser considerado uma pesquisa-ação e delinearemos suas etapas de elaboração, resultados; discussões sobre a implementação e avaliação, na qual estabeleceremos diálogos com os referenciais teóricos; e, na seção final, outras considerações.

\section{Referenciais teóricos}

Ao longo do desenvolvimento do trabalho de doutoramento que deu origem a esse artigo elaboramos outros artigos que estabeleceram razões para a formação dos professores de Ciências a partir de perspectivas de Educação em Direitos Humanos e desenvolvem o modelo de formação de professores Agente Sociocultural e Político (ASCP) no contexto da Educação em Ciências (OLIVEIRA; QUEIROZ, 2013, 2015, 2016a, 2016b, 2016c, 2016d, 2017a, 2017b). Assim, essa seção versará sobre o modelo ASCP e seus desdobramentos com o intuito de facilitar ao leitor a compreensão de nossos objetivos e hipótese. 


\section{Agentes Socioculturais e políticos: um modelo de formação}

Candau et al. (2013) nos estimulam a pensar sobre Direitos Humanos na atualidade, uma vez que o nosso contexto é marcado por um grande interesse e consciência sobre/dos Direitos Humanos, mas carrega, também, uma marca de suas constantes violações. Os autores partem da necessidade de formar professores conscientes e engajados nas questões dos Direitos Humanos, entretanto, para isso, seria urgente uma compreensão de realidade permeada por aspectos culturais e econômicos - influência de autores como Giroux e Maclaren (2011), um saber / conhecer-se como sujeito engajado em lutas sociais, e um grande apreço pelo diálogo e pelos ideais democráticos. Assim, Candau et al. (2013) afirmam que o modelo ASCP é permeado inicialmente pelos elementos: cultura e empoderamento, buscando estimular nos professores a construção de um olhar que permita se indignar com as violações cotidianas, levando-os a uma atitude de enfrentamento. Esse elemento é destacado por Sacavino (2009) a partir da pedagogia do empoderamento - um processo que busca potencializar grupos ou indivíduos sociais que foram postos à margem historicamente. Esse aspecto buscaria estimular que professores fossem capazes de reconhecer assimetrias de poder que permeiam a sociedade, e assim estabelecer um julgamento sobre as lógicas de naturalização das violações de Direitos Humanos, além de propor estratégias que permitam dar voz a grupos e sujeitos postos à margem da sociedade.

Como segundo elemento do modelo os autores destacam a formação de sujeitos de direito. Esse tópico, importante para ser estimulado na formação de professores, implica em desenvolver a percepção de que o direito, quando assegurado pelo Estado, foi ou ainda é fruto de muita luta daqueles que tiveram ou têm na atualidade sua humanidade violada. Destaca-se desse modo nesse elemento a importância das organizações dos grupos de resistência que expressam a voz de uma parcela da população - ONGs, movimentos sociais, grupos de defesa dos Direitos Humanos, entre outros coletivos. Para Candau et al. (2013), ser sujeito de direitos implica em quatro movimentos: (i) saber/conhecer os direitos; (ii) desenvolver uma autoestima positiva; (iii) desenvolver uma capacidade argumentativa; (iv) promover uma cidadania ativa e participante.

A Construção da democracia e diálogo é o terceiro elemento do modelo. Os autores ressaltam que para o fortalecimento da democracia torna-se fundamental pensarmos a Educação em Direitos Humanos como um “[...] exercício da capacidade de indignação articulado ao direito à esperança e admiração da/pela vida, a partir do princípio de equidade que nasce da articulação dos princípios de igualdade e diferença" (CANDAU et al., 2013, p. 47). Um caminho para o estímulo da indignação seria a afirmação do "nunca mais", um princípio de recuperação histórica da memória e do esquecimento das violações de Direitos Humanos com a esperança de que elas não voltem a ocorrer.

Para formar professores a partir do que Candau et al. (2013) consideram como ASCP, um caminho trilhado tem sido o das Oficinas pedagógicas de Direitos Humanos (CANDAU et al., 1996, 2013), consideradas por Andrade e Lucinda (2011) como um lugar onde há relação entre manufatura e "mentefatura", onde mãos e mentes trabalham juntas e articuladas em etapas que valorizam tanto o trabalho coletivo quanto um processo de ensino e aprendizagem que relacione teoria-prática a partir dos momentos ver, saber, celebrar e comprometer-se.

O ver refere-se ao reconhecimento dos saberes prévios. O saber relaciona-se com o aprendizado do novo, o celebrar é a marca do lúdico, a emoção com o novo aprendizado, a alegria das conquistas, e o comprometer-se seria uma resposta à realidade vista anteriormente. Essas 
quatro dimensões se articulam através de três dimensões básicas: (1) sensibilização: ajuda o grupo a entrar no tema e se aproximar das discussões; (2) aprofundamento: um momento mais denso no qual é apresentado um conteúdo de maior complexidade; (3) compromisso: momento no qual são apresentadas sugestões de compromissos efetivos e afetivos que possam ser assumidos individual ou coletivamente. Outros três momentos extras são indicados pelos autores para cursos de formação com durações maiores: (1) a memória, que consiste na lembrança da aula anterior; (2) os objetivos, que devem ficar claros para o planejamento, a execução e a avaliação; (3) a avaliação, que consiste em analisar se os objetivos da oficina foram alcançados.

\section{No contexto da Educação em Ciências}

Nossas reflexões sobre o modelo ASCP permitiram perceber que apesar de ser um modelo adequado à formação de professores, a formação dos professores de Ciências possui a especificidade dos conteúdos - conceituais, procedimentais e atitudinais (ZABALLA 1998) específicos das Ciências da Natureza. É possível destacarmos, por exemplo, os estudos de Johnstone $(1982,2009)$ que falam sobre as dificuldades de aprendizagem de conceitos químicos e da importância de níveis de conhecimento como os macroscópicos, submicroscópicos e representacionais, além de autores como Mortimer, Machado e Romanelli (2000) que destacam a importância de diálogo entre um discurso científico e o cotidiano. A série de estudos existentes em áreas de Ensino-Aprendizagem e Linguagem e Cognição são marcas estruturais da Educação em Ciências. Sendo assim não poderíamos pensar em uma formação de professores de Ciências que se pautasse apenas na Educação em Direitos Humanos, mas que deixasse de lado os conteúdos de Ciências da Natureza. Adicionamos ao modelo ASCP o que chamamos de Conteúdos Cordiais - pedagogização dos conteúdos de Ciências a partir da perspectiva da Educação em Direitos Humanos.

A concepção de pedagogização baseou-se nos trabalhos de Shulman $(1986,1987)$ e da apresentação do modelo consensual feita por Fernandez (2015). Os professores, então, a partir de suas crenças e valores, pedagogizariam conteúdos científicos, ou seja, pensariam e proporiam estratégias sobre como ensinar conteúdos das Ciências da Natureza que vão constituindo o repertório docente. Aspectos mais detalhados dos conteúdos cordiais podem ser vistos em Oliveira e Queiroz (2017a).

\section{A pesquisa-ação}

Barbier (2002) destaca a existência de diversas concepções de pesquisa-ação, mas advoga que algumas noções entrecruzadas as permeiam, ou seja, há compreensões comuns às diferentes noções, entre elas a complexidade, que surge devido à impossibilidade de pensar-fazer pesquisa-ação sem uma apreciação do todo pelas partes e das partes pelo todo, ou seja, na pesquisa-ação não se busca a análise de um determinado dado fora do seu contexto e nem do contexto sem a dimensão analítica. A segunda noção entrecruzada é a escuta sensivvel, entendendo-se então que o pesquisador-interventor deve saber sentir o universo afetivo, imaginário e cognitivo do outro para compreender um pouco do interior, as atitudes, os comportamentos, o sistema de ideias, etc. A terceira, o pesquisador coletivo e a sua escrita, consiste em se ter um grupo de pessoas mobilizadas, líderes de opinião, no universo da população submetida à investigação, 
cujos relatórios devem passar pela discussão entre todos os envolvidos. A quarta noção presente na pesquisa-ação é a dimensão de mudança. A pesquisa ação

[...] visa à mudança de atitudes, práticas, de situações, de condições, de produtos, de discursos... em função de um projeto-alvo que exprime sempre um sistema de valores, uma filosofia de vida, individual e coletiva, suposta melhor do que a que preside à ordem estabelecida. (BARBIER, 2002, p. 106).

Como a pesquisa-ação é concebida com um objetivo de mudança social, as próximas noções entrecruzadas trazidas por Barbier (2002) são negociação e avaliação. A negociação deve estar presente em todo o momento da pesquisa-ação, uma vez que o conflito é inerente a ela. É importante destacar que o clima presente na pesquisa-ação não é de autoritarismo e imposição de uma forma única de ver o mundo, mas de constante avaliação da ação e negociação.

Outra questão apresentada por Barbier (2002) é o conceito de implicação, sendo:

[...] um engajamento pessoal e coletivo do pesquisador, em e por sua práxis científica, em função de sua história familiar e libidinal, de suas posições passada e atual nas relações de produção e de classes, e de seu projeto sociopolítico em ato, de tal sorte que o seu investimento, que é a resultante disso, é parte integrante e dinâmica de toda atividade de conhecimento. (BARBIER, 2002, p.101).

Nosso trabalho apresenta um direcionamento explícito que dialoga com tais noções apresentadas pelo autor, uma vez que, ao se estruturar em uma realidade complexa, apresenta uma visão de mundo implicada, que considera o compromisso com uma formação do professor das Ciências da Natureza que os permita/ possibilite o enfrentamento de racismos, machismos, LGBT-fobias (preconceito contra Lésbicas, Gays, Bissexuais e Transsexuais), permitindo o enfrentamento das desigualdades sociais. Acreditamos que formar o professor em uma cultura de combate ao racismo seja superior à formação do professor em uma perspectiva despreocupada com o racismo. Acreditamos que formar em uma perspectiva de combate ao machismo seja mais válido do que formar para a perpetuação do machismo na sociedade. Acreditamos que formar em uma perspectiva de enfrentamento das LGBT-fobias seja mais digno do que formar com o reforço das LGBT-fobias. Acreditamos que formar para o enfrentamento das desigualdades sociais seja mais digno do que a formação do professor que busca manter a lógica vigente, ou seja, uma formação incapaz de indignar-se com a miséria e a indiferença. Dessa forma, nossa postura de formação é, também, uma postura política que visa a uma mudança social, a mudança na perspectiva de formação de professores de Ciências que contribui como uma das dimensões da mudança social.

A escrita desta pesquisa é uma escrita coletiva materializada em texto por duas mãos, mas produzida em conteúdo por diversas vozes. Foram 16 estudantes e 2 professores envolvidos no projeto sendo que, entre os estudantes, sete cursavam Licenciatura em Química e nove Licenciatura em Biologia. Entre os professores, um deles Licenciado em Química e o outro em Física ambos com compromisso com a avaliação da implementação da ação e com a difusão dos resultados. Para isso o registro de nossa ação foi feito pela gravação em áudio de todas as 
aulas com a utilização de um gravador ${ }^{3}$, com o consentimento de todos os estudantes. Após o encerramento da disciplina, os estudantes foram convidados para a realização de entrevistas individuais semi-estruturadas (LANKSHEAR; KNOBEL, 2008). As entrevistas foram também gravadas em áudio e o material foi todo transcrito segundo as orientações de Lemke (1997) e analisados através de Análise Textual Discursiva (MORAES; GALIAZI, 2011). Destacamos, ainda, que a diversidade do contexto - em nosso caso um curso de formação inicial para licenciandos de Ciências da Natureza - não nos faz aplicar uma metodologia com rigidez, uma vez que o "rígido" não apresenta espaços de mudanças e, por isso, não apresentaria a possibilidade de negociação. Trazemos a metodologia de pesquisa-ação adotada com rigor, reelaborando-a em nosso contexto. Como exemplo de proposta metodológica de pesquisa-ação temos a de Dionne (2007), na qual o autor a apresenta como um processo realizado em 4 fases, 14 etapas e 35 operações. Como adequação ao contexto não realizamos dogmaticamente cada etapa e operação, como sugere Dionne (2007), mas baseamos nossa pesquisa-ação nas quatro fases descritas a seguir: fase 1 (Identificação): descrição da situação inicial e contrato com os colaboradores; formulação do(s) problema(s) iniciais, elaboração da problemática da situação com vista à pesquisa e à ação; fase 2 (projetação): elaboração de hipóteses, definição de objetivos e da pesquisa-ação, formulação de um plano de ação, projetação de uma avaliação da intervenção; fase 3 (realização): avaliação contínua, execução das atividades e implementação da intervenção de pesquisa-ação; fase 4 (avaliação): finalização e reativação da ação, avaliação do processo, difusão dos resultados, análise dos resultados de pesquisa. A manutenção das quatro fases básicas de uma pesquisa-ação - identificação, projetação, realização e avaliação - guarda a sua essência e permite afirmar, então, a nossa proposta como uma pesquisa-ação. A primeira fase trouxe a dimensão das reflexões pessoais, vivências e problematizações sobre o ensino de Ciências, além das reflexões sobre uma Universidade Federal no Norte do país (Brasil) e a formação do professor de Ciências no contexto local. A segunda fase abrange a nossa elaboração de hipótese, plano de ação e reflexões coletivas de avaliação da implementação, realizada ao longo do projeto a partir de seminários e reuniões entre elaboradores da intervenção. A terceira fase contempla a dimensão da execução da atividade de intervenção e da realização da coleta de dados e análises. Na quarta fase as análises permitem a contínua avaliação do processo. Além disso, há a intensa implementação da difusão dos resultados e da experiência vivida no âmbito da formação, a partir de artigos, livros e mídias sociais.

\footnotetext{
${ }^{3}$ Modelo Sony Px-312.
} 


\section{Os resultados}

Com o objetivo de sistematizar as discussões sobre a pesquisa-ação realizada, dividire$\operatorname{mos}^{4}$ esta seção em duas subseções de acordo com as 4 fases apresentadas por Dionne (2007), assim, as fases 1, 2 e 3 - a identificação, projetação e realização - versarão sobre o nosso objetivo prático: elaborar uma disciplina que possibilitasse a formação inicial do professor de Ciências a partir da Perspectiva de Educação em Direitos Humanos e estarão presentes na subseção "da ação". Já a fase 4, intitulada de "avaliação" refere-se ao objetivo de conhecimento: analisar a implementação da disciplina a partir da gravação das aulas e de entrevistas com colaboradores no intuito de compreender o processo formativo dos professores de Ciências como ASCP estará presente na subseção "da investigação". No intuito de analisar a formação dos professores, associamos à fase de avaliação o questionamento investigativo: “[...] os futuros professores de Ciências, ao participarem de uma disciplina elaborada a partir da perspectiva de Educação em Direitos Humanos, apresentam em seus discursos elementos que indicam sua formação como Agentes Socioculturais Políticos?

\section{Da ação}

A proposta de ação surge a partir das reflexões estabelecidas em nossos trabalhos sobre a relevância de uma formação do professor de Ciências que tenha momentos durante o curso ou disciplinas específicas para a discussão de questões sobre Direitos. Em 2014 um dos colaboradores da pesquisa-ação e coautor deste trabalho torna-se professor de uma Universidade Federal no Norte do País e depara-se com a disciplina Cultura Brasileira e Questões étnico-raciais - inserida na Licenciatura em Ciências da Natureza como requisito obrigatório. Desta forma o intuito inicial de criação de uma nova disciplina transforma-se em uma análise e reestruturação da ementa de uma disciplina já existente. Um aspecto importante a ser destacado é que a ementa vigente apresentava um caráter puramente sociológico, ou seja, fazia algumas discussões sobre questões étnico-raciais, mas não se preocupava com aspectos específicos da formação do professor. Assim, a ação foi desenvolvida buscando reunir, na formação dos professores de Química e Biologia, discussões sobre a Educação em Direitos Humanos, a relação entre a Educação em Ciências e a Educação em Direitos Humanos e a questão da pedagogização dos conteúdos de Ciências a partir da perspectiva de Educação em Direitos Humanos.

A reformulação da disciplina, feita com foco na Educação em Direitos Humanos, introduziu temáticas como: a dissociação dos Direitos Humanos de um "Direito de bandidos"; a reflexão sobre preconceito e o conceito de cultura; reflexões sobre igualdade x diferença e sobre a indiferença; os conceitos de máximos e mínimos éticos; e a ideia de banalidade do

\footnotetext{
${ }^{4}$ Dionne (2007) compara a pesquisa-ação a uma Matriosca, também conhecida como boneca russa. Outra comparação bastante cotidiana é a espiral, já que o processo da pesquisa-ação não ocorre de forma linear. Assim, a separação entre o objetivo prático e o objetivo de conhecimento é uma tentativa de facilitar a comunicação sobre as reflexões. Entretanto, será possível observar que a reflexão sobre o objetivo prático também produz conhecimento e a reflexão sobre o objetivo de conhecimento contribui para a reelaboração de práticas e, consequentemente, contribui com a reelaboração dos objetivos de conhecimento, etc.
} 
mal. Além disso, buscou-se apresentar a visão do curso abordando temas como "Mulheres na Ciência", propondo reflexões sobre gênero e machismo; a elaboração de materiais didáticos de Ciências que pretendem ser aliados no enfrentamento do preconceito por origem geográfica, por questões étnico-raciais, sexualidade e gênero; e uma reflexão sobre saberes tradicionais e saberes científicos, oferecendo ainda exemplos de projetos Ciência, Tecnologia, Sociedade e Arte (CTS-Arte). A proposta foi também estimular e solicitar, ao final do curso, a produção pelos alunos de projetos CTS-Arte, oficinas pedagógicas e materiais didáticos sobre os mesmos temas.

A ação foi elaborada em três momentos distintos: (a) abordagem mais geral sobre a Educação em Direitos Humanos; (b) relação entre Educação em Ciências e Educação em Direitos Humanos; (c) pedagogização dos conteúdos de Ciências a partir da perspectiva de Educação em Direitos Humanos. A disciplina manteve o mesmo nome - Cultura Brasileira e questões étnico-raciais - havendo as mudanças aqui descritas em sua ementa.

Dezesseis estudantes se matricularam na disciplina, sendo sete do curso de licenciatura em Química e nove de licenciatura em Biologia. Foram designados a eles os seguintes nomes: Lara, Carolina, Fernanda, Isabel, Renata, Clara, Liz, Acácia, Beatriz, Soraia, Rafaela, Ângela, Raquel, Carla e Jorge. A disciplina foi ministrada durante o oitavo (e último) período dos cursos. Nossa ação formativa de professores de Ciências a partir da perspectiva de EDH, apoiada no esquema de oficinas pedagógicas, deu-se a partir dos seguintes encontros: (1) Oficina Olhares sobre a (in)diferença; (2) Oficina Repensar a cultura; (3) Oficinas Tolerância, máximos e mínimos éticos e $O$ (não tão) simples fato de não nos indignarmos; (4) Oficina Educar em direitos humanos nas aulas de ciências; (5) Atividade a partir da leitura de um texto jornalístico, e definição dos grupos de trabalho e de seus respectivos temas; (6) Oficina Gênero e machismo: lugar de mulher é na ciência; (7) Texto: Território geográfico e seus preconceitos e Oficina 6: Questões étnico-raciais; (8) Oficina Sexualidade e homo-lesbo-trans-fobia: enfretamento necessário; (9) CTS-Arte: Apresentação em slides e leitura de texto; (10) Oficina $O$ diálogo entre os saberes tradicionais e os saberes científicos e apresentações de trabalhos finais (Planejamentos de Ensino-aprendizagem): saberes tradicionais x saberes científicos (Lara, Isabel e Raquel); racismo e questões étnico-raciais no ensino de Ciências (Acácia, Soraia e Rafaela); pobreza e trabalho: as discussões sobre diferentes classes sociais no ensino de Ciências (Carolina e Liz); sexualidade e combate à homo-lesbo-transfobia (Clara e Renata); questões de gênero e uma educação em Ciências que combata o machismo (Ana e Carla); preconceito por origem geográfica e seu enfrentamento a partir de aulas de Ciências (Fernanda e Beatriz); ciência e religiosidade: enfrentamento dos preconceitos por origem religiosa no ensino de Ciências (Jorge e Ângela).

Sobre os aspectos que dificultaram a implementação da ação formativa destacamos: (1) a existência de um pensamento dominante mais conservador, com ideias dissonantes das consolidadas como pertencentes a um espectro que representaria valores presentes na cultura dos Direitos Humanos; (2) a dificuldade no estabelecimento das relações de confiança, dado a uma noção hierárquica entre professor-aluno, própria da estrutura do curso; (3) uma cultura universitária que não valoriza a discordância e o diálogo a ponto de alguns estudantes preferirem o silenciamento ao diálogo. Por outro lado, questões que, após reflexão sobre a ação, aparentam ampliar a facilidade na implementação da ação formativa foram: (1) o projeto ter sido implementado em uma instituição que possui respaldo na comunidade como a Universidade Federal do Tocantins; (2) a universidade ser um espaço que permite disputas e tende a basear-se no pilar da pluralidade, de forma que a ação possuiu espaço para acontecer; (3) a ausência de pessoas 
dispostas a ministrar uma disciplina com tais características antes da chegada do professor que propôs a ação; (4) um contexto de políticas em nível nacional que estimula a formação de professores a partir de uma perspectiva de Educação em Direitos Humanos; (5) a existência de um interesse da área de Educação em Ciências para a discussão de questões sobre Direitos Humanos, o que possibilita a difusão das ideias em termos de publicações em artigos, palestras, livros, etc. como questões que, após reflexão sobre a ação, nos indicam um ambiente favorável a implementação da ação formativa. Sendo assim foi possível afirmarmos que nosso objetivo prático, elaborar uma disciplina que possibilitasse a formação inicial do professor de Ciências a partir da Perspectiva de Educação em Direitos Humanos, foi concluído com sucesso.

\section{Da investigação}

Com o intuito de compreender os processos de formação dos professores de Ciências como ASCP, nossos dados foram coletados a partir de dois momentos distintos: (1) o registro em áudio da implementação da disciplina no curso de Ciências da Natureza; (2) entrevista semiestruturada com alunos dos alunos participantes - elaborada após a implementação da ação. A opção de análise a partir da Análise Textual Discursiva (ATD), desenvolvida por Moraes e Galiazzi (2011) deu origem a quatro episódios, oito categorias e vinte subcategorias que contribuíram para a criação de um panorama interpretativo de nossa ação.

Assim, o Episódio 1 recebeu o título de “a intervenção na voz dos participantes", agregando fragmentos textuais que remetem a reflexões sobre a ação. Duas categorias emergiram a partir deste episódio: categoria 1 - “a voz dos estudantes sobre eles mesmos” -, e categoria 2 - “a voz dos estudantes sobre os não presentes". Na primeira categoria foram agrupados fragmentos textuais que contribuíram para o surgimento das subcategorias:

a) "resistência ao apresentado pela ação", como exemplo, a fala na entrevista de Acácia:

"Mas casos assim... como o de assassinatos, que envolvem a pena de morte, eu acho que têm assim as exceçôs... Mas eu acho que tem pessoa que é ruim... mesmo e por isso que eu não concordo às vežes"; b) "falas de transformação", como na fala na entrevista de Isabel: "Marcou... as discussões levantadas em sala de aula, aí, quando eu vejo algum tipo de preconceito já fico atenta e já, e vou intervindo de algum modo, viu, porque antes eu ficava na minha";

c) "falas de coformação", exemplo da entrevista de Fernanda "Assim, essa questão do negro... eu já batia nessa tecla faz. é tempo...".

A categoria 2 possibilitou o surgimento das subcategorias:

a) "resistências a discussão sobre sexualidade e LGBT-fobias". Como exemplo, a fala na entrevista de Acácia: "Tinha alguns colegas, algumas meninas da turma que, essa questão da homossexualidade foi uma dificuldade por causa da religião... eu não sei se elas... se elas, on se elas não desmascararam, ou falaram que "não, é assim" ou se elas tiverem outro pensamento através da disciplina... Porque eu vejo muito Isso é muita coisa do demônio";

b) "resistências à discussão sobre gênero e machismo": Lara disse em sua entrevista: "um dia depois da aula sobre o machismo, a gente chega mais cedo... ai tinha muito isso... 'ah eu mesmo não tenho nada contra, mas é feio mulher fazer isso, mulher fazer aquilo'... então teve muito isso a ’’.

O Episódio 2, intitulado "famílias e relatos pessoais", possibilitou a criação de duas categorias e cinco subcategorias: categoria 1 - "o mundo percebido" -, do qual emergiram as subcategorias: 
a) "na pele", exemplificada, durante as aulas, pela fala de Clara sobre o machismo do marido: "Professor, a gente já conversou sobre isso, mas não dápra mudar não... ele é muito machista e isso me faz mal... fazer ele mudar é um desafio...";

b) "com os outros", exemplificada pela fala de Clara durante a entrevista sobre percepção da homofobia: "Me deparei com muitos alunos que tinham uma orientação sexual e que não podiam demonstrar isso... eles passavam por muito preconceito. Eu quero ser uma professora diferente". A categoria 2 - "ação no mundo" - possibilitou o surgimento das subcategorias:

a) "silenciamento", exemplificada por Ângela durante as aulas: "O machismo dentro da minha familia é..., discussões sobre opscão sexual é tolerável';

b) "resistência", exemplificada por Acácia durante a sua entrevista: "Não tenho sentimento de indignação quando vejo em algum noticiário que um assassino cruel é condenado à morte. Infelizmente ainda sinto isso. Um tio meu foi brutalmente assassinado, isso acabou destruindo minha família";

c) "transformação/enfrentamento", representada pela fala de Isabel em sua entrevista: "eи vejo até meu marido... em relação a alguns preconceitos... em relação à religião, questão de é... homofobia é... E assim eu tô tentando ter algum diálogo, pra tentar ir abrandando esse preconceito, porque antes não... eu ficava só quieta".

O Episódio 3 surge a partir da percepção do tema sexualidade ter sido um ponto importante para a nossa ação devido aos conflitos gerados durante o semestre de implementação do curso. Sendo assim, o episódio foi intitulado "sexualidades em debate". Nesse episódio emergiram duas categorias e seis subcategorias. A Categoria 1 - "mundo percebido" - possibilitou as subcategorias:

a) "antes da intervenção", exemplificada pelo relato de Ângela durante as aulas sobre sua vivência no colégio: "Ocorreu no $1^{\circ}$ ano do Ensino Médio, quando dois colegas de aula bateram e quase espancaram outro colega de aula nosso, porque o menino em questão era homossexual"; b) “durante/após a intervenção" representada por Lara durante a entrevista: "É a questão de sexualidade... ajudou a repensar... sobre. Porque, por mais que não tinha aquela coisa - 'eu sou preconceituosa, eu sou homofóbica', mas eu ficava pensando assim 'ah.. eu aceito, mas é estranho eu ver o homem... o homem se beijando... quando passa uma mulher com mulher se beijando'. Isso... eu achava estranho e com a disciplina me ajudou a repensar bastante...". A categoria 2 - "ação no mundo" - permitiu o surgimento das subcategorias:

a) "silenciamento", representada pela interação em sala de aula quando o Professor pergunta: "O que você faria quando você percebe que um estudante tem sofrido com ameaças e piadas de colegas de sala após se assumir como homossexual?” e Raquel responde: "conversar com a turma sobre o assunto, ressaltando que devemos respeitar o próximo independente de sua opção sexual'. Entretanto, posteriormente, Raquel pede para ser retirada do trabalho final sobre sexualidades e LGBT-fobias;

b) "resistência à formação", exemplificada com a frase de Raquel em uma interação durante as aulas: "hoje em dia se discute muito sobre o que é preconceito... mas até que ponto isso é bom ou não? Porque do jeito que as coisas caminham a pessoa já se sente ofendida...";

c) "coformação", como, por exemplo, na fala de Ana durante a apresentação do trabalho sobre sexualidades: "Achei legal que uma pessoa com a formação igual a da Clara consiga ter uma mudança de visão como essa que ela apresenta... nesse grupo você conseguiu aquilo que você queria, né [professor]? Cair no sorteio, justamente a pessoa que tinha mais preconceito com o tema"; 
d) "transformação", exemplificada pela fala de Clara durante sua entrevista: "Esse trabalho foi marcante na minha vida... E eu tenho certeza que o dia que eu entrar numa sala de aula [...] Eu quero ser uma professora diferente".

Por fim, o Episódio 4, intitulado "a docência em Ciências" surge a partir da busca pela compreensão sobre a formação docente e no interesse de entender como os estudantes colaboradores elaboraram as relações entre suas percepções de docência e as proposições feitas durante a ação a partir da perspectiva de Educação em Direitos Humanos adotada pelo curso. Esse episódio possibilitou o surgimento de duas categorias: 1 - "ser professor de Ciências" -, que fez emergir as subcategorias:

a) "a escolha profissional", representada pela fala de Lara: "sinceramente eu prestei porque era menos concorrido... Quimica... é o menos concorrido";

b) "a prática do professor de Ciências", exemplificada pelos dizeres de Isabel: "Por mais que eu tente dar meu conteúdo, sempre vão surgir essas questões. E essas questões são envolvidas na ciência, no mundo que vivemos... então, né?! É ciência e está embasado nesses estudos que a gente teve em sala de aula... é muito importante você saber se posicionar numa sala de aula em diversas situações que podem vir a ocorrer, né??'.

A Categoria 2 - "os conteúdos de conteúdos de Ciências" - fez emergir as subcategorias a) "a seleção dos conteúdos", representada pela fala de Carolina: "Por que a gente escolhen o tema do garimpo? Porque o Brasil atualmente ocupa uma posição de destaque mundial na produção de ouro... [...] na atividade de aprofundamento a gente colocou 'a extração do ouro: do garimpo à joalheria'... vai envolver vários processos quimicos como o uso do mercúrio [...]. Eles usam o mercúrio elementar na forma líquida, fazem a amalgamaşão... depois colocam no forno para separar o mercúrio do ouro... o forno faz. o vapor do mercurio subir e é possivel extrair o ouro...", e;

b) "os discursos de pedagogização dos conteúdos", representado por Acácia na fala :"CTS-Arte contribui para o empoderamento de sujeitos e grupos minorizados bistoricamente. No caso a gente escolbeu os Xerente e as comunidades quilombolas [...] no caso a CTS-Arte vai buscar resgatar a memória cultural desses povos, dessa cultura. Então o exemplo que a gente resolven trabalhar foi o artesanato do capim dourado".

Ao estabelecermos caminhos para a implementação do modelo proposto por Candau et al. (2013), desenvolvemos a interpretação do Educador em Ciências como Agente Sociocultural e Político a partir de três dimensões. A primeira foi chamada de "perceber a realidade", sendo nela importante, como já citado, que o professor consiga interpretar o mundo a partir das relações culturais e sociais que existem na sociedade, percebendo as assimetrias de poder, injustiças e constantes violações. A segunda dimensão foi chamada de "posicionamento diante de uma realidade percebida" - pois acreditamos que, a partir do momento em que a pessoa consegue estabelecer um olhar para a sociedade que possibilite interpretar o mundo entendendo as assimetrias de poder, desigualdades sociais e outros tipos de injustiças existentes, ela passa a ter a opção de se posicionar, sendo possível adotar uma das duas posições: a indiferença ou a indignação. O professor como Agente Sociocultural e Político opta por se indignar. A terceira dimensão foi chamada de "intervenção educativa" e engloba o estabelecimento de uma leitura de mundo e a decisão por um posicionamento, que sejam motores para intervenções educativas que problematizem as questões dos Direitos Humanos e possibilitem, dentro de cada disciplina, uma ação mais humanizada de mundo para/com os estudantes. 
A partir da análise realizada, a primeira percepção que destacamos é de que a implementação de um curso sobre Educação em Direitos Humanos na formação dos professores de Ciências da Natureza não é uma ação isolada no mundo, ou seja, o processo de formação é interpelado simultaneamente por diversas relações sociais. Desta forma, não se pode afirmar que exista algum tipo de formação na qual o conteúdo formativo seja extremamente dissociado das histórias de vida e dos valores construídos no âmbito das relações pessoais e interpessoais. Uma ação sobre Educação em Direitos Humanos é extremamente relacionada com questões como: as relações estabelecidas entre o estudante e ele mesmo - ou seja, o processo de reflexões pessoais -, as relações entre o professor implementador e os estudantes, as relações entre estudantes, as relações entre os estudantes e outros professores da universidade, as relações entre os estudantes e suas famílias, as relações entre os estudantes e os movimentos sociais, entre os estudantes e os seus amigos, a relação entre os estudantes e as igrejas ou outros centros de produção de saberes/valores religiosos.

Assim, uma característica marcante do processo que vivemos foi a relação entre os conteúdos abordados, as questões pessoais vivenciadas, histórias com amigos e as respectivas famílias. É também no ato de reflexão sobre essas questões que podemos perceber aspectos característicos da formação dos colaboradores como Educadores Agentes Socioculturais e Políticos.

Outro ponto possível de ser destacado é que o ambiente de disputa entre valores possibilitou alguns posicionamentos durante a implementação, fazendo surgir assim o silenciamento, a resistência, a coformação e a transformação. O silenciamento, a resistência e a transformação ocorreram quando imperaram as divergências entre os valores apresentados pela proposta de curso e os valores considerados como importantes para os estudantes em suas relações de vida e reflexões pessoais. No caso do silenciamento há divergência, mas também há uma opção do colaborador pelo não diálogo e pelo não conflito. Diversos fatores contribuem para entender uma posição como essa, sendo, entre eles, a existência de uma hierarquia entre professorcolaboradores dada pelo fato de o curso pertencer a uma rotina institucional; uma cultura universitária que durante todos os anos da graduação reprime as discordâncias entre estudantes e professores e não estimula a elaboração de diálogos; a não consideração do curso como algo provocante a ponto de merecer os argumentos daquele estudante, etc. Já a resistência indica a divergência, porém, nos traz a percepção de que a hierarquia existente entre professor-estudantes não é mais forte do que a vontade de discordância, uma vez que os estudantes resistentes se sentiram em um ambiente no qual a discordância não os prejudicaria, ou seja, em um ambiente democrático. Por fim, o processo de transformação também é dado por uma discordância inicial entre os valores propostos pelo curso e os valores trazidos pelo estudante, fruto de suas reflexões e de suas relações no mundo, porém, percebe-se o apreço por novas formas de ver o mundo e vontade de diálogo. A interação compreendida como coformação aconteceu quando os valores apresentados pela ação e os valores dos colaboradores entraram em consonância, levando assim os estudantes colaboradores a atuarem no ambiente formativo reforçando os valores apresentados pelo curso a partir de argumentações, tentativas de sensibilização e debates.

Como já citamos anteriormente, não é possível acreditar que todos os estudantes colaboradores se apresentaram nos mesmos processos de interação (silenciamento, ou coformação, etc.) para todos os temas. Isso nos conduz a um segundo ponto importante, no que se refere ao nosso objetivo de conhecimento, a dimensão "caleidoscópica” dos colaboradores e da formação. 
Ao estudarmos sobre um modelo que estabelece diretrizes para a formação de professores engajados socialmente nas discussões e pertencentes à cultura dos Direitos Humanos podemos imaginar que um processo formativo seja algo quase que fabril. Nesse imaginário sobre formação, os estudantes colaboradores passariam de um curso que os moldaria ao que prega a Educação em Direitos Humanos. Entretanto, Cortina (2005) nos alerta sobre a importância de ir para além de uma Educação em Direitos Humanos com características impositivas: "É preciso reconhecer que o grotesco teológico pode ser convertido hoje num 'grotesco político' se continuarmos a recitar a cansativa cantilena dos Direitos Humanos e da democracia liberal sem fundamentá-los na inteligência e no sentimento de pessoas de carne e osso" (CORTINA, 2005, p. 15).

O que nos assegura o caráter democrático e baseado no diálogo do processo implementado na formação de professores é a percepção que chamamos de caleidoscópica dos colaboradores.

O caleidoscópio é um aparelho óptico formado por um pequeno tubo de papel, plástico ou metal, que possui pequenos fragmentos de vidro colorido ao fundo. Com a incidência da luz pelo lado oposto ao do observador e em uma combinação com espelhos uma combinação variada de efeitos visuais surge a cada movimento. Esse instrumento pode contribuir como uma analogia lúdica para exemplificarmos e compreendermos o processo de formação que vivenciamos. Foi possível perceber que não existe uma orientação de pensamento em todos os temas com todos os estudantes colaboradores. Ou seja, um estudante que possui uma sensibilidade para a questão étnico-racial não necessariamente será sensível para questões sobre sexualidade e um estudante sensível para questões sobre sexualidade, não necessariamente possuirá valores de questionamento a questões de classe social, e assim por diante. A imensa possibilidade de combinações à qual atribuímos a dimensão caleidoscópica permeia, portanto, a formação do professor como Agente Sociocultural e Político. Às vezes um determinado colaborador desenvolve um pensamento ao qual podemos atribuir um status de pertencente a uma gama de formas de pensar/agir, características de um Agente Sociocultural e Político, porém, isso não se repete para outro tema. Isso se relaciona diretamente com o aspecto abordado anteriormente - uma dimensão inseparável entre o processo formativo e a construção dos valores em cada situação vivida nas interações entre os colaboradores e suas famílias, amigos, etc. No espectro do que chamamos de Dimensão Caleidoscópica, é possível afirmar que nem sempre a sensibilização para determinadas lutas em detrimento de outras é um caso de desenvolvimento de uma solidariedade com os outros diferentes.

A essa gama de estudantes existe um duplo desafio, o de enfatizá-los como sujeitos de direito, pertencentes a uma luta, mas sem deixar apagar a sensibilidade para questões externas às de seus respectivos grupos.

Outro ponto destacado na análise foi sobre a docência, tendo sido possível perceber que, de acordo com um curto relato dos colaboradores que se predispuseram a dar entrevista, muitos dos estudantes não possuíam interesse pela docência. Entre os oito entrevistados, apenas um revelou interesse inicial pela carreira docente e, em nível de Brasil, é possível perceber que as respostas dos licenciandos sobre a docência entram em harmonia com o investigado por Tartuce, Nunes e Almeida (2010) sob o título de "Alunos do ensino médio e atratividade da carreira docente no Brasil". As autoras identificam que apenas $2 \%$ entre os estudantes de 8 públicas e 10 particulares, em um total de 1.501 alunos de diversos locais do Brasil, demonstraram interesse pela docência. 
Essa percepção sobre a docência nos traz uma dupla interpretação. A primeira nos faz refletir sobre as dificuldades que existem em formar professores de Ciências que não possuem interesse em ser professores, mas que fazem, em uma maioria, um curso devido à facilidade de entrada na universidade ou no mercado de trabalho docente, ou por outros motivos diferentes. A segunda reflexão está no âmbito do ouvido durante as entrevistas, nas quais a maioria dos dizeres relacionava as aprendizagens durante a intervenção com aspectos do campo pessoal. Os entrevistados, de maneira geral, refletiram sobre docência apenas no final da entrevista quando questionados explicitamente sobre o tema. Acreditamos que essa característica nas entrevistas seja marca na proximidade dos temas discutidos no curso das questões presentes no ambiente familiar de cada colaborador, porém, o fator desinteresse pela carreira docente faz com que os estudantes colaboradores estabeleçam as reflexões sobre o que foi abordado no curso a partir daquilo que vivem ou viverão, ou seja, em espaços diferentes do ambiente escolar - foco principal dos cursos de licenciatura. Sendo assim, iniciamos pensando a formação de professores como Agentes Socioculturais e Políticos, porém, nossa vivência formativa contribuiu para percebermos que o professor Agente Sociocultural e Político não se afasta do Educador Agente Sociocultural e Político. Iniciamos pensando na Educação Formal, porém, precisamos pensar na formação em um sentido mais amplo. Para isso, trazemos Brandão (2007) que, ao refletir sobre a Educação, apresenta o ensinar e aprender como algo existente entre os bichos e que, como entre nós, humanos, existe em toda parte. Assim, o autor tenta "corrigir a visão estreita de que a Educação se confunde com a Escolarização e se encontra só no que é 'formal', 'oficial', 'programado', ‘técnico', ‘tecnocrático”'. (BRANDÃO, 2007, p. 100).

Brandão (2007) nos ajuda no exercício de entender que a Educação está, como processo, em diversos âmbitos e para muito além daquilo que é uma escolarização formal. Assim, mesmo quando os estudantes colaboradores não refletem sobre a escola e trazem suas percepções para questões familiares, de caráter de reflexões pessoais, interações entre amigos e etc., eles estão, também, apresentando uma formação como Educadores Agentes Socioculturais e Políticos.

Tendo em vista a diferenciação que propomos entre o Professor como Agente Sociocultural e Político e o Educador como Agente Sociocultural e Político - diferenciação não estabelecida inicialmente por Candau et al. (2013) -, a indissociabilidade entre os processos formativos dos professores de Ciências a partir da perspectiva de Educação em Direitos Humanos e a percepção da dinâmica caleidoscópica identificada durante o processo de formação, podemos afirmar, até o momento, que todos os colaboradores que se propuseram a dar entrevistas apresentaram indicativos da construção de elementos que nos fazem percebê-los como Educadores Agentes Socioculturais e Políticos para determinados temas: demonstrações de apreço pelo valor do diálogo, por leituras de mundo que compreendam as assimetrias de poder associadas a questões culturais e econômicas, além de apresentarem indicativos da vontade de empreender mudanças.

A dimensão profissional ficou clara na análise do $4^{\circ}$ episódio. Assim, se no quesito vontade de ser professor os entrevistados demonstraram majoritariamente um desinteresse diante da carreira docente, no que se refere ao restabelecimento das reflexões sobre o oficio do professor de Ciências da Natureza, percebemos nos estudantes entrevistados amplo consenso com nossa percepção de comprometimento social no exercício da profissão docente, demonstrada por todos os estudantes colaboradores entrevistados, tendo sido a marca na elaboração dos planejamentos de ensino-aprendizagem, nos quais pôde-se perceber que, mediante a formação 
específica que pensou a dimensão da relação entre os conteúdos específicos das Ciências da Natureza e os conteúdos específicos da Educação em Direitos Humanos, foi possível a elaboração de planejamentos de ensino-aprendizagem para aulas de Ciências como espaços que estimulem a formação de cidadãos do mundo.

É preciso reconhecer nossas limitações e entendermos que há uma diferença entre o ato de planejar, a implementação de uma prática e a consolidação de uma cultura científica e escolar pautada nos Direitos Humanos. Entretanto. Nossa categoria, que emergiu a partir da análise de nossa ação, confirmou a possibilidade de, mediante a formação específica, professores de Ciências da Natureza abordarem seus conteúdos específicos sem deixar de lado aspectos fundamentais à formação cidadã construídos pela Educação em Direitos Humanos. Assim, no que se refere à dimensão técnica da formação docente, destacamos nossa intervenção de forma bastante positiva. Com exceção do grupo sobre sexualidades, todos os planejamentos apresentados demonstraram relação entre conteúdos de Ciências e uma pedagogização que buscou discutir questões referentes aos Direitos Humanos. Após a análise foi elaborado um evento com caráter de diálogo para que fosse possível estabelecer a negociação com os participantes sobre as interpretações provenientes das fases da pesquisa-ação - a identificação, projetação e realização que estabeleceram relações mais estreitas com o objetivo prático e a fase de avaliação que estabeleceu relação com o objetivo de conhecimento. Em síntese, a análise destes Episódios, categorias e subcategorias nos permitiu a reflexão sobre o objetivo de conhecimento, dando origem às seguintes considerações: (1) durante a implementação de uma ação pedagógica sobre Educação em Direitos Humanos o processo é interpelado por valores provenientes das diversas relações sociais, ou seja, os conteúdos formativos, devido ao seu caráter de formação em valores, apresentam-se em constante processo de disputa. Os valores apresentados pelo curso como bons valores para apreciar, e como valores importantes aos educadores como Agentes Socioculturais e Políticos, estão em disputa com valores provenientes das relações estabelecidas entre o estudante e ele mesmo, e do estudante com outros. Esse processo de disputa estabeleceu posicionamentos durante a implementação, como o silenciamento, a resistência, a coformação e a transformação. O silenciamento, a resistência e a transformação ocorreram quando imperaram as divergências entre os valores apresentados pela proposta de curso e os valores considerados como importantes para os estudantes em suas relações de vida e reflexões pessoais. Já a coformação aconteceu quando os valores apresentados pela ação e os valores dos colaboradores entraram em consonância; (2) há uma fragmentação dos posicionamentos de cada estudante colaborador para cada diferente tema abordado, ou seja, um estudante que possui uma sensibilidade para a questão étnico-racial, não necessariamente será sensível para questões sobre sexualidade, assim como um estudante que está sensível para questões sobre sexualidade não necessariamente possuirá valores de questionamento a questões de classe social, etc. Essa dimensão é inseparável do processo formativo que implementamos e da relação de disputas entre os valores presentes na cultura dos Direitos Humanos e as interações vividas por cada colaborador em sua vida, com suas reflexões, suas famílias, amigos, etc. Essa questão chamamos de dimensão caleidoscópica da formação. É possível perceber nessa interpretação o que Barbier (2002) trata como implicação. Entender que os colaboradores apresentam posições mais relacionadas com valores dos Agentes Socioculturais e Políticos para uns temas do que para outros, e que esse é um processo de construção temporal; (3) estabelecemos a diferenciação entre o Educador como Agente Sociocultural e Político e o Professor como Agente 
Sociocultural e Político, sendo possível afirmar a atuação dos colaboradores como Educadores Agentes Socioculturais e Políticos; (4) foi possível perceber que, apesar do majoritário desinteresse pela carreira docente, as reflexões sobre a docência mostraram consonância com a visão da docência em Ciências da Natureza reforçada pelo curso. Além disso, foi possível perceber que os colaboradores conseguiram estabelecer relações entre os conteúdos conceituais e procedimentais de suas disciplinas específicas e propostas de pedagogização pautadas em aspectos da Educação em Direitos Humanos como: (a) o empoderamento de grupos historicamente marginalizados; (b) formação de sujeitos de direito; (c) recuperação das violações de Direitos Humanos e consolidação de uma cultura do "nunca mais"; (d) estímulo ao diálogo e apreço pela construção da democracia.

A análise realizada faz com que o trabalho empreendido tenha alcançado também o objetivo de conhecimento. Dessa forma, ao questionamento associado ao objetivo de conhecimento "os futuros professores de Ciências, ao participarem de uma disciplina elaborada a partir da perspectiva de Educação em Direitos Humanos, apresentam em seus discursos elementos que indicam sua formação como Agentes Socioculturais Políticos?”, respondemos positivamente.

Entretanto, um processo de formação em Direitos Humanos é um processo de formar-se em Direitos Humanos. Assim, o processo de formar estudantes, futuros professores, também forma o professor formador e é nessa troca que construímos confiança, uma troca em que elaboramos parcerias, sensibilizamos aos outros e nos sensibilizamos. A oportunidade de elaborar, implementar e analisar com uma pesquisa-ação um curso sobre Educação em Direitos Humanos é incrível, porém, não podemos nos iludir. Uma avaliação crítica do trabalho é fundamental e, nesse intuito, foi possível perceber que seria importante a dedicação de um tempo maior para a discussão dos temas - violência urbana, criminalidade e sistema prisional; sexualidade feminina. Ambos os temas foram destacados nos diversos discursos dos entrevistados como situações problemáticas e temos certeza que foi dado pouco espaço para essas discussões. A elaboração de um curso com carga horária um pouco maior permitiria a incorporação de novos temas e isso já está sendo feito a partir da nova elaboração do documento pedagógico dos cursos de Ciências da Natureza da universidade em questão. No curso de Química já foi aprovada como obrigatória a disciplina de Direitos Humanos e diversidades na aula de Ciências, um reflexo do que foi a implementação de nosso curso. A disciplina obrigatória trará estudantes menos dispostos ao diálogo e exigirá do professor formador maior capacidade de diálogo e de mediar possíveis conflitos. Entretanto, avaliamos como positivo esse desafio. Uma lacuna importante detectada foi a elaboração de uma aula final com uma roda de discussões sobre tudo que aconteceu ao longo do período. Essa percepção também será incorporada em futuras organizações da disciplina.

\section{Outras considerações}

Seria bastante ousado dizer que o processo formativo, por si, garantiu a formação de professores como Agentes Socioculturais e Políticos. A análise de nossa ação nos mostrou que o processo foi muito mais amplo e se relacionou com aspectos da história de vida e sobre como cada colaborador, ao logo dessa história, valorou positivamente ou negativamente determinados aspectos. Foi possível afirmar que os professores formadores que buscarem implementar cursos 
similares em suas universidades encontrarão, na maioria das vezes, um campo de disputa entre os valores apresentados pelo curso e os valores de cada estudante participante. Isso faz parte do processo e é característico de temas tão relacionados com a nossa vida como são os temas que estão no espectro do abordado pelos Direitos Humanos.

Ainda foi possível perceber que cada estudante colaborador estabeleceu valores diferentes a questões diferentes, assim, alguém que possuía uma visão mais liberal para o aspecto das sexualidades não necessariamente foi alguém sensibilizado para a questão étnico-racial e vice-versa. Assim como não necessariamente uma pessoa que se opôs à lógica "olho por olho, dente por dente" estava sensibilizada para questões de gênero. Essa complexidade humana fez com que não pudéssemos afirmar a relação direta entre a elaboração de um curso pautado nas discussões sobre Direitos Humanos e a formação dos professores como Agentes Socioculturais e Políticos. Porém, afirmamos que a presença de uma ação que discutiu Direitos Humanos, na formação de professores de Ciências, contribuiu para o árduo caminho que é ser Educador/ Professor como Agente Sociocultural e Político. É possível afirmar, então, que a formação contribuiu porque proporcionou acesso a discussões que antes estariam em outros ambientes que não o universitário. No que diz respeito à formação dos professores de Ciências da Natureza, abriu um espaço para ouvir o outro, aprender com os outros diferentes, tentar se desconstruir e pensar por outras lógicas não-hegemônicas; estimulou o diálogo sobre temas que, em outros contextos, são tabus; apresentou seu viés ideológico sem se travestir de uma falsa neutralidade, trazendo a prática política para um âmbito pedagógico e proporcionando uma pedagogia que pense, também, de forma política. Acreditamos que contribuiu porque tentou abalar estruturas de pensamento e não se opôs a divergências entre os modos de pensar o mundo; possibilitou o surgimento de um precioso espaço para discussões sobre docência em Ciências e uma cultura de Direitos Humanos.

\section{Referências}

ANDRADE, M.; LUCINDA, M. C. Oficinas pedagógicas em direitos humanos: uma aposta de formação política com grupos populares. In: CANDAU, V. M.; SACAVINO, S. (Org.). Educar em tempos difíceis: construindo caminhos. Rio de Janeiro: 7 Letras, 2011. p. 253-271.

BARBIER, R. A pesquisa-ação. Brasília: Plano, 2002.

BRANDÃO, C. R. O que é educação. São Paulo: Brasiliense, 2007.

BRASIL. Ministério da Educação. Conselho Nacional de Educação. Resolução no 2, de $\mathbf{1}^{\mathbf{0}}$ de julho de 2015. Define as diretrizes curriculares nacionais para a formação inicial em nível superior (cursos de licenciatura, cursos de formação pedagógica para graduados e cursos de segunda licenciatura) e para a formação continuada. Disponível em: $<$ https://tinyurl.com/ y85ula8h>. Acesso em: 26 abr. 2018. 
Oliveira, R. D. V. L.; Queiroz, G. R. P. C.

CANDAU, V. M. et al. Educação em direitos humanos e formação de professores. São Paulo: Cortez, 2013.

CANDAU, V. M. et al. Tecendo a cidadania: oficinas pedagógicas de direitos humanos. Petrópolis: Vozes, 1996.

CORTINA, A. Cidadãos do mundo: para uma teoria da cidadania. São Paulo: Loyola, 2005.

DIONNE, H. A pesquisa-ação e o desenvolvimento local. Brasília: Liber, 2007.

FERNANDEZ, C. Revisitando a fase de conhecimentos e o conhecimento pedagógico do conteúdo (PCK) de professores de ciências. Ensaio, Belo Horizonte, v. 17, n. 2, p. 500-528, 2015.

GIROUX, H.; MACLAREN, P. Formação do professor como uma esfera contrapública: a pedagogia radical como uma forma de política cultural. In: MOREIRA, A. F; SILVA, T. T. (Org.). Currículo, cultura e sociedade. São Paulo: Cortez, 2011. p. 141-172.

LANKSHEAR, C.; KNOBEL, M. Pesquisa pedagógica: do projeto à implementação. Porto Alegre: Artmed, 2008.

JOHNSTONE, A. H. Macro and microchemistry. The School Science Review, London, v. 64, n. 227, p. 377-379, 1982.

JOHNSTONE, A. H. You can't get there from here. Journal of Chemical Education, Easton, v. 87, n. 1, p. 22-29, 2010.

LEMKE, J. L. Aprender a hablar ciencia: lenguaje, aprendizaje y valores. Barcelona: Paidós, 1997.

MORAES, R.; GALIAZZI, M. C. Análise textual discursiva. Ijuí: Ed. Unijuí, 2011.

MORTIMER, E. F.; MACHADO, A. H.; ROMANELLI, L. I. A proposta curricular de química do Estado de Minas Gerais: fundamentos e pressupostos. Química Nova, São Paulo, v. 23, p. 273-283, 2000.

OLIVEIRA, R. D. V. L. A formação de professores de ciências em uma perspectiva de educação em direitos humanos. 2017. 371 f. Tese (Doutorado) - Centro Federal de Educação Tecnológica Celso Suckow da Fonseca, Rio de Janeiro, 2017.

OLIVEIRA, R. D. V. L.; QUEIROZ, G. R. P. C. Conteúdos cordiais: química humanizada para uma escola sem mordaças. São Paulo: Livraria da Física, 2017a.

OLIVEIRA, R. D. V. L.; QUEIROZ, G. R. P. C. O cotidiano, o contextualizado e a educação em direitos humanos: a escolha de um caminho para uma educação cidadã cosmopolita.

Revista Iberoamericana de Educación, Madrid, v. 71, n. 1, p. 75-96, 2016b.

OLIVEIRA, R. D. V. L.; QUEIROZ, G. R. P. C. Educação em ciências e direitos

humanos: reflexão-ação em/para uma sociedade plural. Rio de Janeiro: 2013. 
OLIVEIRA, R. D. V. L.; QUEIROZ, G. R. P. C. La formación de profesores de ciencias en la perspectiva de la educación en derechos humanos: por los caminos de una razón cordial.

Revista Electrónica Interuniversitaria de Formación del Profesorado: REIFOP, Murcia, v. 19, n. 2, p. 1-14, 2016 a.

OLIVEIRA, R. D. V. L.; QUEIROZ, G. R. P. C. Olhares sobre a (in)diferença: formarse professor de ciências a partir de uma perspectiva de educação em direitos humanos. São Paulo: Livraria da Física, 2015.

OLIVEIRA, R. D. V. L.; QUEIROZ, G. R. P. C. Planejar com direitos humanos na formação de professores de ciências. Revista Areté: revista amazônica de ensino de ciências, Manaus, v. 10, n. 22, p. 231-245, jul. 2017b.

OLIVEIRA, R. D. V. L.; QUEIROZ, G. R. P. C. Professores de ciências como agentes socioculturais e políticos: a articulação valores sociais e a elaboração de conteúdos cordiais. Redequim: revista debates em ensino de química, Recife, v. 2, n. 2, 2016 c.

OLIVEIRA, R. D. V. L.; QUEIROZ, G. R. P. C. (Org.). Tecendo diálogos sobre direitos humanos na educação em ciências. São Paulo, Livraria da Física, 2016d.

SACAVINO, S. Democracia e educação na America Latina. Petrópolis: DP et alii: Novamérica, 2009.

SHULMAN, L. S. Knowledge and teaching: foundations of the new reform. Harvard Educational Review, Cambridge, v. 57, n. 1, p. 1-22, 1987.

SHULMAN, L. S. Those who understand: knowledge growth in teaching. Educational Researcher, Washington, v. 15, n. 2, p. 4-14, 1986.

TARTUCE, G. L. B. P.; NUNES, M. M. R.; ALMEIDA, P. C. A. Alunos do ensino médio e atratividade da carreira docente no Brasil. Cadernos de Pesquisa, São Paulo, v. 40, n. 140, p. 445-477, 2010.

ZABALA, A. A prática educativa: como ensinar. Porto Alegre: Artmed, 1998.

Artigo recebido em 28/06/2017. Aceito em 07/11/2017.

Contato: Universidade Federal de Uberlândia, Rua Vinte, 1600, Tupã, Ituiutaba, MG, CEP 38304-402, Brasil. 